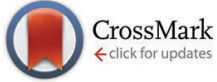

Cite this: Phys. Chem. Chem. Phys., 2017, 19, 3232

Received 30th November 2016 Accepted 19th December 2016

DOI: $10.1039 / c 6 c p 08193 b$

www.rsc.org/pccp

\title{
Influence of metal coordination and co-ligands on the magnetic properties of 1D Co(NCS) 2 coordination polymers $\uparrow$
}

\author{
Michat Rams, ${ }^{a}$ Zbigniew Tomkowicz, ${ }^{a}$ Michael Böhme, ${ }^{b}$ Winfried Plass, ${ }^{b}$ \\ Stefan Suckert, ${ }^{C}$ Julia Werner, ${ }^{C}$ Inke Jess ${ }^{c}$ and Christian Näther*c
}

\begin{abstract}
Two new transition metal thiocyanate coordination polymers with the composition [Co(NCS) 2 (4vinylpyridine $\left.)_{2}\right]_{n}$ (1) and $\left.\left[\mathrm{Co}(\mathrm{NCS})_{2} \text { (4-benzoylpyridine }\right)_{2}\right]_{n}$ (2) were synthesized and their crystal structures were determined. In both compounds the Co cations are octahedrally coordinated by two transcoordinating 4-vinyl- or 4-benzoylpyridine co-ligands and four $\mu$-1,3-bridging thiocyanato anions and linked into chains by the anionic ligands. While in 1 the $\mathrm{N}$ and the $\mathrm{S}$ atoms of the thiocyanate anions are also in trans-configuration, in $\mathbf{2}$ they are in cis-configuration. A detailed magnetic study showed that the intra-chain ferromagnetic coupling is slightly stronger for $\mathbf{2}$ than for $\mathbf{1}$, and that the chains in both compounds are weekly antiferromagnetically coupled. Both compounds show a long range magnetic ordering transition at $T_{\mathrm{C}}=3.9 \mathrm{~K}$ for 1 and $T_{\mathrm{C}}=3.7 \mathrm{~K}$ for 2 , which is confirmed by specific heat measurements. They also show a metamagnetic transition at a critical field of $450 \mathrm{Oe}$ (1) and $350 \mathrm{Oe}$ (2), respectively. Below $T_{c} \mathbf{1}$ and $\mathbf{2}$ exhibit magnetic relaxations resembling relaxations of single chains. The exchange constants obtained from magnetic and specific heat data are in good accordance with those obtained from constrained DFT calculations carried out on isolated model systems. The ab initio calculations allowed us to find the principal directions of anisotropy.
\end{abstract}

\section{Introduction}

During the last few decades, the development of strategies for the rational synthesis of new molecular magnetic materials with desired physical properties has attracted increasing interest. ${ }^{1-14}$ In this context $1 \mathrm{D}$ magnetic compounds that show a slow relaxation of magnetization like, e.g., single-chain magnets (SCMs) are of special interest, because they are able to store a magnetic moment for a long time, and therefore, they have some potential for future applications. ${ }^{14-21}$ This might be one of the reasons why an increasing number of such compounds were recently reported and some selected examples are given in the reference list. ${ }^{22-40}$ For the synthesis of such compounds cations of large magnetic anisotropy must be connected by ligands into

\footnotetext{
${ }^{a}$ Institute of Physics, Jagiellonian University, Eojasiewicza 11, 30-348 Kraków, Poland

${ }^{b}$ Institut für Anorganische und Analytische Chemie, Universität Jena, Humboldtstr. 8, 07743 Jena, Germany

${ }^{c}$ Institut für Anorganische Chemie, Christian-Albrechts-Universität zu Kiel, Max-Eyth-Straße 2, 24118 Kiel, Germany.E-mail: cnaether@ac.uni-kiel.de $\dagger$ Electronic supplementary information (ESI) available: Crystal data and ORTEP plots, IR, XRPD, magnetic and specific heat data with analysis, DFT models and spin densities, numerical results of calculations. CCDC 1507089 (1), and 1507085 (2). For ESI and crystallographic data in CIF or other electronic format. See DOI: 10.1039/c6cp08193b
}

1D magnetic chains with a high ratio between intra- and interchain interactions. Therefore, for optimization of the properties of such materials systematic investigations of the influence of chemical and structural modification on their magnetic properties might be helpful.

We have recently reported on a family of coordination compounds of composition $\left[\mathrm{Co}(\mathrm{NCX})_{2}(\mathrm{~L})_{2}\right]_{n}(\mathrm{X}=\mathrm{S}$, Se and $\mathrm{L}=\mathrm{N}$-donor co-ligand), in which $\mathrm{Co}(\mathrm{II})$ cations are octahedrally surrounded by two trans-coordinating $\mathrm{N}$ and two $\mathrm{S}$ atoms of thioor two Se of selenocyanate anions and two trans-coordinating neutral N-donor co-ligands and linked by pairs of anionic ligands into linear chains (Fig. 1). ${ }^{41-52}$ This is a common arrangement for such compounds, even if in some cases also other topologies like, e.g., layers or dimers are observed. ${ }^{53-57}$ Independent of the fact that although similar co-ligands are used, the compounds with the chain structures can be divided into two different groups: in one group, the compounds exhibit an antiferromagnetic (AF) ground state and show a metamagnetic transition. The magnetic relaxations observed for these compounds can be traced back to that of single chains. ${ }^{41-44}$ In contrast, the compounds of the second group exhibit a ferromagnetic (FO) ground state and the relaxations observed in the $\mathrm{AC}$ measurements might not be traced back to the relaxation of single chains. ${ }^{46,47}$ It is noted that for all of these compounds two different arrangements of the 


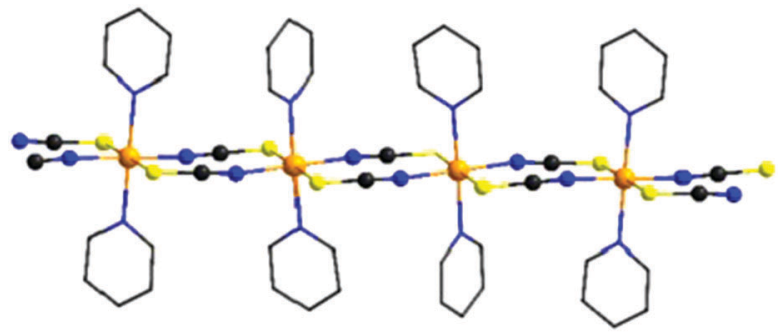

Fig. 1 View of one chain in the crystal structures of compounds of the general composition $\left[\mathrm{Co}(\mathrm{NCX})_{2}(\mathrm{~L})_{2}\right]_{n}(\mathrm{X}=\mathrm{S}$, Se; $\mathrm{L}=$ neutral $\mathrm{N}$-donor coligand). For clarity, only the 6 -membered rings of the different co-ligands are shown and the hydrogen atoms are omitted.

chains are found. In one group the $\mathrm{N}-\mathrm{N}$ vectors to the $\mathrm{N}$-donor co-ligand are parallel, whereas in the second group half of them are canted (Fig. S1 in ESI $\dagger$ ). However, these two different arrangements are not obviously correlated to the magnetic ground state of these compounds, because for each group (AF or FO) examples are observed, with $\mathrm{N}-\mathrm{N}$ vectors of neighboring chains parallel or canted. ${ }^{42-47}$

For the present study we chose 4-vinylpyridine (Scheme 1) which is topologically very similar to 4-ethylpyridine reported earlier and which differs only by two $\mathrm{H}$ atoms. In this case it would be of interest to find out which structure the vinylpyridine compound will adopt and what will be its magnetic ground state in comparison to 4-ethylpyridine. We also chose the larger 4-benzoylpyridine (Scheme 1) as co-ligand, for which longer inter-chain distances are expected but surprisingly a compound was obtained, in which the $\mathrm{N}$ and $\mathrm{S}$ atoms of the anionic ligands are cis-oriented, whereas the co-ligands are still trans to each other. This coordination is different from that observed in all other compounds of this family and allows us to study the influence of a slightly different metal coordination on the magnetic properties.

It is noted that for these two co-ligands the crystal structures of compounds of composition $\mathrm{Co}(\mathrm{NCS})_{2}$ (4-vinylpyridine $)_{4}$ as well as $\mathrm{Co}(\mathrm{NCS})_{2}$ (4-benzoylpyridine $)_{4}$ were already reported, where the 4-vinylpyridine compound existed in two polymorphic modifications. ${ }^{58-60}$ These compounds consist of discrete complexes, in which the $\mathrm{Co}$ (II) cations are octahedrally coordinated by two terminal N-bonded thiocyanato anions and four N-coordinating co-ligands. Moreover, the crystal structure of a compound of composition $\mathrm{Co}(\mathrm{NCS})_{2}$ (4-vinylpyridine $)_{2}$ was also reported, that
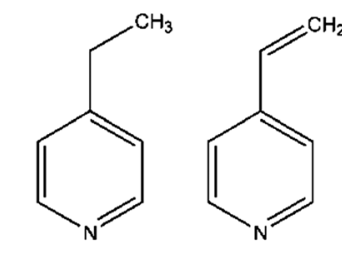

4-Fuhylpyridine 4-Vinylpyridine

Scheme 1<smiles>O=C(c1ccccc1)c1ccncc1</smiles>

4-Benzoylpyridine

(1) exactly corresponded to the composition expected for the desired chain compound. However, this compound consisted of discrete complexes in which the Co(II) cations were tetrahedrally coordinated by two terminal thiocyanato anions and two 4-vinylpyridine co-ligands. ${ }^{59}$

In this article the crystal structures of two new chain compounds are presented together with their magnetic characterization. The aim of this paper is detailed comparative studies of DC and AC magnetic properties and specific heat measurements as well as $a b$ initio and DFT calculations of relevant magnetic parameters. Among others, we would also like to see if there is any influence of the cis vs. trans coordination of the Co cations on the magnetic properties.

\section{Experimental section}

\section{Syntheses}

4-Benzoylpyridine, 4-vinylpyridine and $\mathrm{Co}(\mathrm{NCS})_{2}$ were obtained from Alfa Aesar. All solvents were used without further purification.

Synthesis of $\left[\mathrm{Co}(\mathrm{NCS})_{2}(\mathbf{4} \text {-vinylpyridine })_{2}\right]_{\boldsymbol{n}}$ (1). Single crystals were synthesized by the reaction of $\mathrm{Co}(\mathrm{NCS})_{2}(26.3 \mathrm{mg}, 0.15 \mathrm{mmol})$ and 4-vinylpyridine $(16.0 \mu \mathrm{L}, 0.15 \mathrm{mmol})$ in a mixture of $0.5 \mathrm{~mL}$ of water and $0.5 \mathrm{~mL}$ of ethanol. After one week suitable single crystals were obtained.

A crystalline powder on a larger scale was obtained by reacting $\mathrm{Co}(\mathrm{NCS})_{2}(175.1 \mathrm{mg}, 1.00 \mathrm{mmol})$ and 4-vinylpyridine $(215.7 \mu \mathrm{L}$, $2.00 \mathrm{mmol}$ ) in $2.0 \mathrm{~mL}$ of acetonitrile for $3 \mathrm{~d}$. Elemental analysis: calcd (\%) for $\mathrm{C}_{16} \mathrm{H}_{14} \mathrm{CoN}_{4} \mathrm{~S}_{2}$ : C 49.87, $\mathrm{H}$ 3.66, N 14.54, S 16.64; found $\mathrm{C} 48.42, \mathrm{H} 3.68, \mathrm{~N} 14.55, \mathrm{~S}$ 16.64. IR (ATR, $\left.\mathrm{cm}^{-1}\right): \nu_{\max }=$ $3069(\mathrm{w}), 2987(\mathrm{w}), 2893(\mathrm{w}), 2354(\mathrm{w}), 2320(\mathrm{w}), 2100(\mathrm{~s}), 1610(\mathrm{~s})$, 1545 (m), 1503 (m), 1413 (m), 1223 (m), 1066 (w), 1014 (m), 987 (s), $934(\mathrm{~s}), 934(\mathrm{~s}), 798(\mathrm{~m}), 642(\mathrm{w}), 566(\mathrm{~m})$.

Synthesis of Co(NCS $)_{2}$ (4-benzoylpyridine $)_{2}$ (2). Single crystals of compound 2 were obtained by the reaction of $\mathrm{Co}(\mathrm{NCS})_{2}$ (52.5 mg, $0.30 \mathrm{mmol}$ ) and 4-benzoylpyridine (27.5 mg, $0.15 \mathrm{mmol}$ ) in $1.5 \mathrm{~mL}$ of ethanol at $80{ }^{\circ} \mathrm{C}$ for $3 \mathrm{~d}$. Single crystals were formed on the edge of the reaction vessel but some of them consisted of the discrete complex $\mathrm{Co}(\mathrm{NCS})_{2}$ (4-benzoylpyridine $)_{4} \cdot{ }^{58}$ A pure crystalline powder on a larger scale could be obtained by stirring $\mathrm{Co}(\mathrm{NCS})_{2}$ (26.3 mg, $0.15 \mathrm{mmol}$ ) and 4-benzoylpyridine (55 mg, $0.30 \mathrm{mmol}$ ) in $1.5 \mathrm{~mL}$ of ethanol at $80{ }^{\circ} \mathrm{C}$ for $3 \mathrm{~d}$. Elemental analysis: calcd (\%) for $\mathrm{C}_{26} \mathrm{H}_{18} \mathrm{CoN}_{4} \mathrm{O}_{2} \mathrm{~S}_{2}$ : C 57.67, $\mathrm{H} 3.35, \mathrm{~N}$ 10.35, S 11.84; found $\mathrm{C} 56.467, \mathrm{H} 3.25, \mathrm{~N} 10.15, \mathrm{~S}$ 11.73. IR $\left(\right.$ ATR, $\left.\mathrm{cm}^{-1}\right): \nu_{\max }=3393(\mathrm{w}), 3305(\mathrm{w}), 3062(\mathrm{w}), 2896(\mathrm{w}), 2132$ (m), 2111 (s), 1660 (s), 1589 (m), 1545 (m), 1446 (m), 1410 (m), 1313 (m), 1277 (s), 1219 (m), 1151 (m), 1063 (m), 1015 (m), 935 (s), 839 (s), 792 (s), 697 (s), 643 (s), 576 (m).

\section{X-Ray powder diffraction (XRPD)}

The XRPD measurements were performed by using (1) a PANanalytical X'Pert Pro MPD Reflection Powder Diffraction System with $\mathrm{CuK} \alpha$ radiation $(\lambda=154.0598 \mathrm{pm})$ equipped with a PIXcel semiconductor detector from PANanalytical and (2) a Stoe Transmission Powder Diffraction System (STADI P) with $\mathrm{CuK} \alpha$ radiation that was equipped with a linear position-sensitive MYTHEN detector from STOE \& CIE. 


\section{IR spectroscopy}

FT IR spectra were recorded on a Genesis series FTIR spectrometer, by ATI Mattson, in $\mathrm{KBr}$ pellets, as well as by using an Alpha IR spectrometer from Bruker equipped with a Platinum ATR QuickSnap ${ }^{\mathrm{TM}}$ sampling module between 375 and $4000 \mathrm{~cm}^{-1}$.

\section{Elemental analysis}

CHNS analysis was performed using an EURO EA elemental analyzer, fabricated by EURO VECTOR Instruments and Software.

\section{Single-crystal structure analyses}

Data collection was performed using an imaging plate diffraction system IPDS-2 (1 and 2) with Mo-K ${ }_{\alpha}$-radiation from STOE \& CIE. The structure solutions were performed by direct methods using SHELXS-97 and structure refinements were performed against $F^{2}$ using SHELXL-97. All non-hydrogen atoms were refined with anisotropic displacement parameters. The hydrogen atoms were positioned with idealized geometry and were refined isotropically with $U_{\text {iso }}(\mathrm{H})=-1.2 \cdot U_{\text {eq }}(\mathrm{C})$ using a riding model. In 1 a part of the co-ligand is disordered and was refined using a split model. For 2 the absolute structure was determined and is in agreement with the selected setting (Flack $x=0.014(16)$ by classical fit to all intensities and 0.012(6) from 1487 selected quotients (Pearson's method)). Selected crystal data are shown in Table S1 (ESI $\dagger$ ). CCDC 1507089 (1), and CCDC 1507085 (2) contain the supplementary crystallographic data for this paper.

\section{Magnetic measurements}

Magnetic measurements were performed for polycrystalline samples using a Quantum Design MPMS XL magnetometer. In order to avoid reorientation of grains in a magnetic field the powders were mixed with Nujol and frozen below $250 \mathrm{~K}$ with zero field. Diamagnetic corrections of sample holders and the core diamagnetism were subtracted.

\section{Specific heat measurements}

Specific heat was measured by the relaxation technique using the Quantum Design PPMS. Powders were pressed without any binder into a thin pellet. Apiezon $\mathrm{N}$ grease was used to ensure thermal contact of the samples with the microcalorimeter. The heat capacity of the calorimeter with the grease was measured before each run and subtracted subsequently.

\section{Computational details}

In the DFT calculations the positions of the non-hydrogen atoms have been taken from the crystal structures of $\mathbf{1}$ and $\mathbf{2}$, which we use as initial molecular structures for the different computational models (see Computational studies). The positions of all hydrogen atoms were optimized using the Turbomole 6.6 package of programs ${ }^{61}$ at the RI-DFT ${ }^{62-65} / \mathrm{BP}^{66,67} / \mathrm{def} 2-\mathrm{SVP}^{68}$ level of theory. For these optimizations $\mathrm{Co}$ (II) ions have been replaced by diamagnetic $\mathrm{Zn}$ (II) ions to achieve a faster SCF convergence and to save computational time. In the case of $\mathbf{1}$ and $\mathbf{2}$ the magnetic coupling constants have been calculated within constrained DFT $(\mathrm{CDFT})^{69,70}$ and broken-symmetry DFT (BS-DFT) approaches.
In both cases the B3LYP hybrid functional ${ }^{66,71,72}$ in combination with def2-TZVPP (Co), def2-TZVP (S, N), and def2-SVP (remaining atoms) basis sets ${ }^{68}$ was used. CDFT calculations have been performed with NWChem $6.6^{73}$ whereas Turbomole 6.6 was used for BS-DFT calculations. Within the CDFT calculations two spin constraints that contained the specific Co(II) ion and its six donor atoms were applied to perform the high-spin state (HS) and broken-symmetry (BS) state calculations. Subsequently, the magnetic coupling constant $J$ was calculated by eqn (1) with $S_{\mathrm{A}}=S_{\mathrm{B}}=3 / 2$ for a Heisenberg Hamiltonian $\left(\mathcal{H}=-J S_{1} S_{2}\right)$.

$$
J=\frac{E_{\mathrm{BS}}-E_{\mathrm{HS}}}{8 S_{\mathrm{A}} S_{\mathrm{B}}}
$$

In the case of BS-DFT the coupling constant was obtained by Yamaguchi's approach ${ }^{74,75}$ (see eqn (2)).

$$
J=\frac{2\left(E_{\mathrm{BS}}-E_{\mathrm{HS}}\right)}{\left\langle S_{\mathrm{HS}}{ }^{2}\right\rangle-\left\langle S_{\mathrm{BS}}{ }^{2}\right\rangle}
$$

To obtain the single-ion magnetic properties of $\mathbf{1}$ and 2 ab initio calculations have been performed with Molcas 8.0 SP1. ${ }^{7-79}$ In all cases CASSCF calculations with 7 electrons in 10 orbitals ( $3 \mathrm{~d}$ and $4 \mathrm{~d}$ shells) were carried out which included 10 quartet states $\left({ }^{4} \mathrm{~F},{ }^{4} \mathrm{P}\right)$ and 40 doublet states $\left({ }^{2} \mathrm{G},{ }^{2} \mathrm{P},{ }^{2} \mathrm{H},{ }^{2} \mathrm{D},{ }^{2} \mathrm{D},{ }^{2} \mathrm{~F}\right)$. Additionally, scalar relativistic effects were employed with a second-order Douglas-Kroll-Hess (DKH) Hamiltonian in combination with ANO-RCC basis sets (Co and donor atoms: ANO-RCC-VTZP; other atoms: ANO-RCC-VDZ). ${ }^{80-82}$ Subsequently, dynamic correlation was treated with CASPT2 on the basis of the CASSCF wave functions for 10 quartet and the 12 lowest doublet states. The RASSI-SO method was employed to treat mixing of states with different multiplicities and to include spin-orbit coupling. Finally, the SINGLE_ANISO module on the basis of the RASSI-SO wave function was used to obtain single-ion anisotropies.

\section{Results and discussion}

Synthetic aspects and crystal structures of compounds 1 and 2

The reaction of equimolar amounts of cobalt(thiocyanate) with 4-vinylpyridine, respectively 4-benzoylpyridine, leads to the formation of the two new compounds 1 and 2. If more co-ligand is used the known complexes $\mathrm{Co}(\mathrm{NCS})_{2}$ (4-vinylpyridine) $)_{4}$ and $\mathrm{Co}(\mathrm{NCS})_{2}$ (4-benzoylpyridine $)_{4}$ are formed. ${ }^{58,60} \mathrm{IR}$ spectroscopic investigations revealed the $\mathrm{CN}$ stretching vibration at values of $2100 \mathrm{~cm}^{-1}$ (1) and $2111 \mathrm{~cm}^{-1}$, respectively $2132 \mathrm{~cm}^{-1}$ (2), clearly indicating that in these compounds the $\mathrm{Co}$ (II) cations are linked by the anionic ligands (Fig. S2 and S3, ESI $\dagger$ ). This is somehow surprising, because, as mentioned above, a compound of composition $\mathrm{Co}(\mathrm{NCS})_{2}$ (4-vinylpyridine) $)_{2}$ was already reported to form discrete tetrahedral complexes, for which a value for the CN stretch of about $2050 \mathrm{~cm}^{-1}$ is expected. ${ }^{59}$ Therefore, it is highly likely that a different modification was obtained, using the synthesis from solution.

$\left.\left[\mathrm{Co}(\mathrm{NCS})_{2} \text { (4-vinylpyridine }\right)_{2}\right]_{n}$ (1) crystallizes in the triclinic space group $P \overline{1}$ with 2 formula units in the unit cell. The asymmetric unit consists of two crystallographically independent Co(II) cations, which are located on centers of inversion, and two 
thiocyanato anions as well as two 4-vinylpyridine ligands in general positions (Fig. S4, ESI $\dagger$ ). In the crystal structure, the Co cations are always trans-coordinated by the two $\mathrm{N}$ - and two S-bonding thiocyanato anions as well as two co-ligands and this is the usual coordination observed in this family of compounds. The Co-N bond lengths of 2.050(2) and 2.164(2) $\AA$ and the Co-S bond lengths of 2.5862(7) and 2.6051(7) $\AA$ are comparable to those in similar compounds (Table S1, ESI $\dagger$ ). The Co(II) cations are linked into chains by pairs of thiocyanato anions via a $\mu$-1,3-bridging coordination (Fig. 2, top).

The 4-benzoylpyridine compound 2 crystallizes in the orthorhombic space group $P 2{ }_{1} 2_{1} 2_{1}$ with four formula units in the unit cell. The asymmetric unit consists of one Co cation, two thiocyanato anions and two 4-benzoylpyridine ligands (Fig. S5, ESI $\dagger$ ). The Co cations are octahedrally coordinated by two $\mathrm{N}$ - and two S-bonding thiocyanato anions as well as two $\mathrm{N}$-bonding co-ligands, with bond lengths and angles comparable to that in $\mathbf{1}$ (Table S3, ESI $\dagger$ ). As in compound 1, the N-donor co-ligands are still trans-coordinated but for the anionic ligands a cis-coordination is found that was never observed before in this class of compounds. The Co(II) cations are linked by pairs of $\mu$-1,3-bridging anionic ligands into linear chains (Fig. 2, bottom). The intra-chain distances between the Co centers amount to $5.653 \AA$ in compound 1 and to $5.588 \AA$ in compound 2 (Table 1 ). The longest inter-chain distance is observed for the 4-vinylpyridine compound, which is somehow surprising, because 4-benzoylpyridine is the larger ligand. However, this might be traced back to the different arrangement of the chains in the crystal (see below).

In 1 the $\mathrm{N}$ vectors of the co-ligands of neighboring chains are all parallel, which belongs to one of the two possible arrangements of

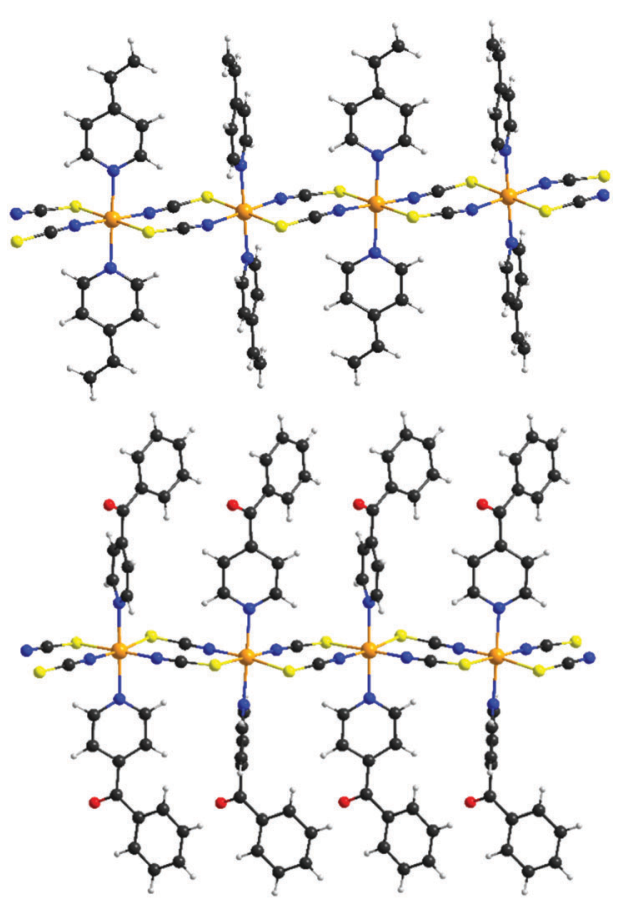

Fig. 2 View of the cobalt thiocyanato chains in compound 1 (top) and 2 (bottom). An ORTEP plot of both compounds can be found in Fig. S4 and $\mathrm{S} 5$ in $\mathrm{ESI} . \dagger$
Table 1 Intra- and the shortest inter-chain Co ...Co distances in $\mathbf{1}$ and $\mathbf{2}$

\begin{tabular}{lll}
\hline Compound & Intra-chain/Å & Inter-chain/Å \\
\hline $\mathbf{1}$ & 5.653 & 8.174 \\
$\mathbf{2}$ & 5.588 & 6.755
\end{tabular}

chains in this family of compounds (Fig. S6, ESI $\dagger$ ). It is noted that this arrangement is different from that in $\left[\mathrm{Co}(\mathrm{NCS})_{2}\right.$ (4-ethylpyridine $\left.)_{2}\right]_{n}$, in which the $\mathrm{N}-\mathrm{N}$ vectors are canted. This is somehow surprising, because as mentioned in the Introduction, both ligands are structurally very similar, and therefore, similar crystal structures are expected. However, the 4-benzoylpyridine compound adopts the arrangement in which the $\mathrm{N}-\mathrm{N}$ vectors are canted (Fig. S6, ESI $\dagger$ ).

Based on the structural data, the powder pattern for compounds $\mathbf{1}$ and $\mathbf{2}$ was calculated and compared with the experimental pattern, which shows that most compounds were obtained as pure crystalline phases (Fig. S7 and S8, ESI†).

\section{Magnetic investigations - static properties}

To get information about the magnetic ground state of $\mathbf{1}$ and $\mathbf{2}$, the magnetic susceptibility $\chi$ was measured as a function of temperature in a weak magnetic field of 100 Oe (Fig. 3, inset). The temperature dependence of the $\chi T$ product is shown in the main part of Fig. 3 to illustrate the simultaneous action of the spin-orbit interaction of the Co(II) ion and of the dominant intra-chain magnetic interaction. They nearly compensate each other above $100 \mathrm{~K}$, but below $50 \mathrm{~K}$ the $\chi T$ product strongly increases, pointing that the dominant interaction is ferromagnetic.

To understand the low temperature magnetic behavior it should be taken into account that the Co(II) ion in an octahedral axially distorted coordination is well described with the effective spin $s=1 / 2$ and a strongly anisotropic $g$ factor. To estimate relevant magnetic parameters of the chain of Ising spins we used the Hamiltonian

$$
\mathcal{H}=-J \sum_{j} s_{j}^{z} s_{j+1}^{z}+\mu_{\mathrm{B}} \sum_{j} H \cdot \widehat{g} \cdot s_{j}
$$

where the magnetic field $H$ is close to zero and the $\hat{g}$ tensor includes $g$-factors parallel and perpendicular to the spin easy

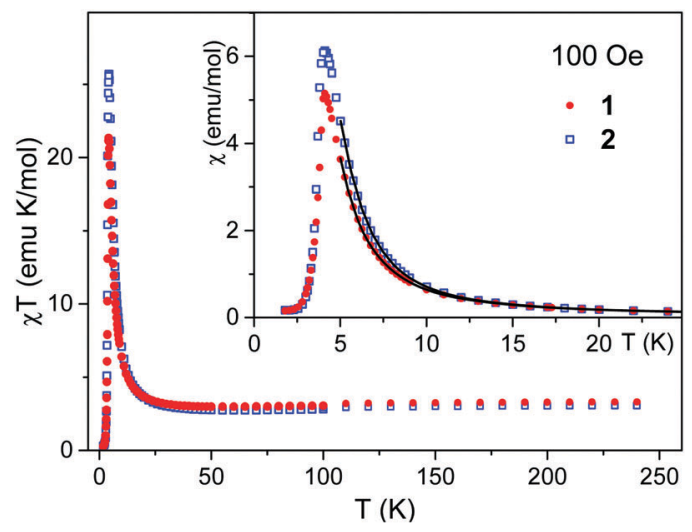

Fig. 3 Temperature dependence of the $\chi^{T}$ product (main figure) and of the magnetic susceptibility $\chi$ (inset) measured in magnetic field of $100 \mathrm{Oe}$ for $\mathbf{1}$ and $\mathbf{2}$. Solid lines are from fits (see text). 
axis. The equations derived by Fisher ${ }^{83}$ for the susceptibility along these directions are

$$
\begin{gathered}
\chi_{\|}^{\text {chain }}=\frac{N_{\mathrm{A}} \mu_{\mathrm{B}}^{2} g_{\|}^{2}}{4 k_{\mathrm{B}} T} \exp \left(\frac{J}{2 k_{\mathrm{B}} T}\right) \\
\chi_{\perp}^{\text {chain }}=\frac{N_{\mathrm{A}} \mu_{\mathrm{B}}^{2} g_{\perp}^{2}}{2 J}\left[\tanh \left(\frac{J}{4 k_{\mathrm{B}} T}\right)+\frac{J}{4 k_{\mathrm{B}} T} \operatorname{sech}^{2}\left(\frac{J}{4 k_{\mathrm{B}} T}\right)\right]
\end{gathered}
$$

For $J>0$ the parallel susceptibility strongly dominates and is responsible for the exponential increase of $\chi T$ at low temperatures. When chains are weakly interacting this inter-chain interaction may be taken into account by using the following equation of the mean field approximation: ${ }^{84}$

$$
\chi_{i}=\chi_{i}^{\text {chain }} /\left(1-\frac{z J^{\prime}}{N_{\mathrm{A}} g_{l}^{2} \mu_{\mathrm{B}}{ }^{2}} \chi_{i}^{\text {chain }}\right),
$$

where index $i$ denotes the direction of magnetic field parallel or perpendicular to the easy axis, $\chi$ is the susceptibility of the system with weekly interacting chains and $\chi^{\text {chain }}$ is the susceptibility of isolated chains. The parameter $z J^{\prime}$ is a measure of the interchain interaction. For powder samples the final equation for susceptibility is

$$
\chi=\left(\chi_{\|}+2 \chi_{\perp}\right) / 3 .
$$

The temperature dependence of the $\chi T$ product was fitted with the above model in various temperature ranges (e.g. 5-50 K). In the fitting procedure also an additive constant $a$ (like a TIP, the temperature independent paramagnetism) was added to susceptibility. It also takes into account the increase of $\chi T$ with increasing temperature due to the spin-orbit interaction. This procedure is correct in the limited temperature range. The best fit parameters are given in Table 2 .

In this context it is noted that $J$ values obtained directly from the slope of the $\ln (\chi T)$ vs. reciprocal temperature curve (Fig. S9, ESI $\dagger$ ) are considerably lower than those obtained from the fit. The difference might originate from the antiferromagnetic inter-chain interaction or from deviation of $\mathbf{1}$ and $\mathbf{2}$ from assumptions of the Hamiltonian given in eqn (3).

Magnetization versus temperature was measured also in the zero-field cooled and field cooled (FC/ZFC) regime (Fig. 4). In low magnetic fields an antiferromagnetic maximum is observed but in higher fields a metamagnetic transition occurs. No bifurcations between ZFC and FC curves are observed for compound 1. For 2 small bifurcations are observed in the field range up to 500 Oe. These bifurcations are hardly seen in the

Table 2 Parameters obtained from the analysis of dc magnetic data for 1 and 2

\begin{tabular}{lll}
\hline Compound & $\mathbf{1}$ & $\mathbf{2}$ \\
\hline$T_{\mathrm{c}}(\mathrm{K})$ & $3.90(5)$ & $3.70(5)$ \\
$J / k_{\mathrm{B}}(\mathrm{K})$ & $27(3)$ & $32(2)$ \\
$g_{\|}$ & $7.3(2)$ & $7.0(2)$ \\
$g_{\perp}$ & $0.0(1)$ & $0.0(1)$ \\
$z J^{\prime} / k_{\mathrm{B}}(\mathrm{K})$ & $-0.27(2)$ & $-0.24(2)$ \\
$a\left(\mathrm{emu} \mathrm{mol}^{-1}\right)$ & $0.0098(7)$ & $0.0076(6)$
\end{tabular}
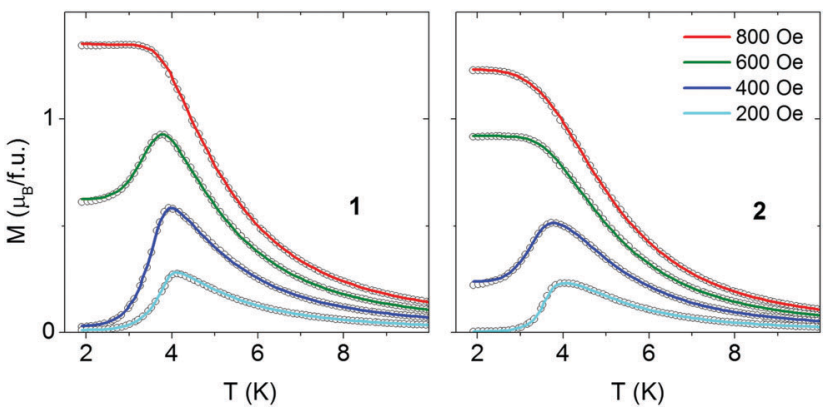

Fig. 4 Temperature dependence of magnetization recorded for 1 (left) and $\mathbf{2}$ (right) in various magnetic fields following zero-field cooling (open points) and field cooling (lines).

scale of Fig. 4 but they are better visible in the $\chi v s . T$ presentation (Fig. S10, $\mathrm{ESI} \dagger$ ).

Field dependent magnetization curves, measured at $1.8 \mathrm{~K}$ in the high field range, are shown in Fig. 5. No saturation is observed even at high fields, which is in accordance with the high magnetic anisotropy of $\mathrm{Co}(\mathrm{II})$ ions. The magnetization at high fields is slightly higher for $\mathbf{1}$ than for $\mathbf{2}$, which may originate from the different coordination of $\mathrm{Co}$ (II) in both compounds.

The field dependent magnetization was also separately measured in weak fields. The experimental data collected at $1.8 \mathrm{~K}$ are presented in the inset of Fig. 5. They were recorded in the field cycling between -1 and +1 kOe. Data collected at higher temperatures can be found in Fig. S11-S13 in ESI. $\dagger$ It is seen that below $T_{\mathrm{c}}$ a magnetization jump occurs. This jump observed in the field $H_{\mathrm{c}}$ of $\sim 450$ Oe for 1 and $\sim 350$ Oe for 2 at $1.8 \mathrm{~K}$ is a sign of metamagnetic transition. No hysteresis loop is observed for 1 down to $1.8 \mathrm{~K}$. For 2 a narrow hysteresis loop is observed in the field range 250-500 Oe and a second small jump near 0 Oe, the origin of which is not clear to us (Fig. S14, ESI $\dagger$ ).

$M(H)$ plots made in the field range 0-1000 Oe for 1 and 2 at various temperatures (Fig. S12 and S13, ESI $\dagger$ ) were used to construct the phase diagrams (Fig. 6). However, points below 150 Oe in these diagrams were determined as the maximum of $\mathrm{d}(\chi T) / \mathrm{d} T$ to reach an agreement with the specific heat study

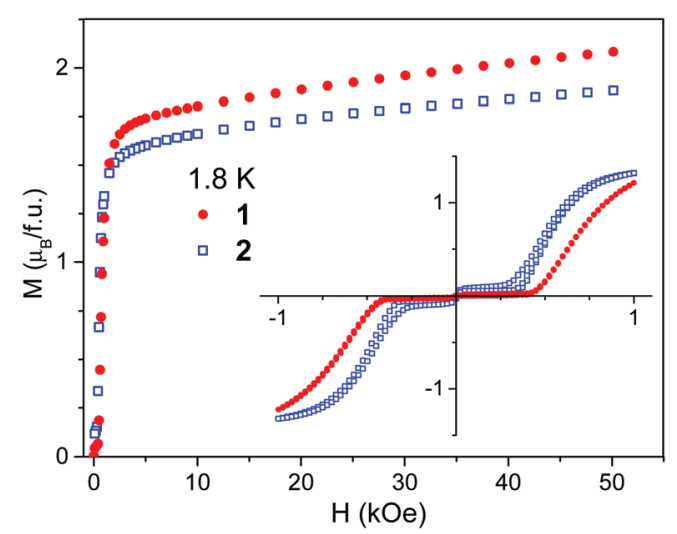

Fig. 5 Field dependent magnetization measured at $1.8 \mathrm{~K}$ for compounds 1 and $\mathbf{2}$. Inset shows magnetic hysteresis loops registered in the low field range. 


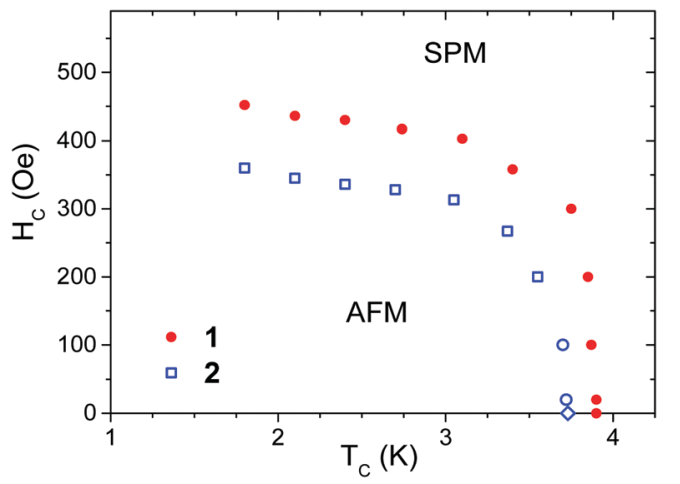

Fig. 6 Magnetic phase diagram of $\mathbf{1}$ (solid dots) and $\mathbf{2}$ (open squares) with antiferromagnetic (AFM) and saturated paramagnetic (SPM) phases.

(Fig. S15, ESI $\dagger$; see below). The relation between $\mathrm{d}(\chi T) / \mathrm{d} T$ and magnetic specific heat was derived by Fisher for simple antiferromagnets ${ }^{85}$ but also tested for a variety of antiferromagnets. ${ }^{86}$

\section{Specific heat measurements}

To confirm the long range magnetic ordering in compounds $\mathbf{1}$ and 2, specific heat $(C)$ measurements were performed (Fig. 7). The temperature dependence of $C$ measured at different applied fields is shown in Fig. S16 and S17 (ESI $\dagger$ ). A distinct peak of $C(T)$ is present at $3.80 \mathrm{~K}$ for 1 , and at $3.68 \mathrm{~K}$ for 2 , which marks the onset of the second order magnetic ordering transition, in good agreement with the results of magnetic measurements.

The field of $0.4 \mathrm{kOe}$ shifts the peak for 1 to a bit lower temperature, $3.75 \mathrm{~K}$, which is typical for an antiferromagnetic structure. For 2 the field of 0.4 kOe is already above the critical field (see Fig. 6) and the $C(T)$ peak is completely reduced. The observed peaks of specific heat are on the background that originates from the crystal lattice vibrations, but also from magnetic exchange interaction within chains of Co(II) ion spins. To calculate the lattice contribution we used the linear combination of the Debye and Einstein models of the phonon density of states to account for both acoustic and optical phonon bands.

Below $40 \mathrm{~K}$ it was enough to assume a single acoustic branch described by $\theta_{\mathrm{D}}$ and a single optical branch described by $\theta_{\mathrm{E}}$, producing together

$$
C_{\text {lattice }}=A_{\mathrm{D}} C_{\text {Debye }}\left(T, \theta_{\mathrm{D}}\right)+A_{\mathrm{E}} C_{\text {Einstein }}\left(T, \theta_{\mathrm{E}}\right)
$$

The exchange contribution to the molar specific heat is described by

$$
C_{\text {chain }}=N_{\mathrm{A}} k_{\mathrm{B}}\left(J / 4 k_{\mathrm{B}} T\right)^{2} \operatorname{sech}^{2}\left(J / 4 k_{\mathrm{B}} T\right)
$$

for $s=1 / 2$ Ising spins in chains. The exchange constant $J$ is defined by the Hamiltonian given in eqn (3).

This model, however, does not contain inter-chain interaction, and cannot explain long range ordering. For this reason, the sum $C_{\text {lattice }}+C_{\text {chain }}$ was fitted to $C / T$ data in the range from 4.5 to $40 \mathrm{~K}$, i.e. only above the critical temperature. For 1 we obtained $\theta_{\mathrm{D}}=77.2(5) \mathrm{K}, \theta_{\mathrm{E}}=148.5(1.8) \mathrm{K}, A_{\mathrm{D}}=1.88(3)$, $A_{\mathrm{E}}=4.36(7) \mathrm{J}(\mathrm{mol} \mathrm{K})^{-1}$, and $J / k_{\mathrm{B}}=28.8(4) \mathrm{K}$. For 2 we obtained $\theta_{\mathrm{D}}=79.8(0.6) \mathrm{K}, \theta_{\mathrm{E}}=149(2) \mathrm{K}, A_{\mathrm{D}}=2.46(4), A_{\mathrm{E}}=4.96(7) \mathrm{J}(\mathrm{mol} \mathrm{K})^{-1}$,

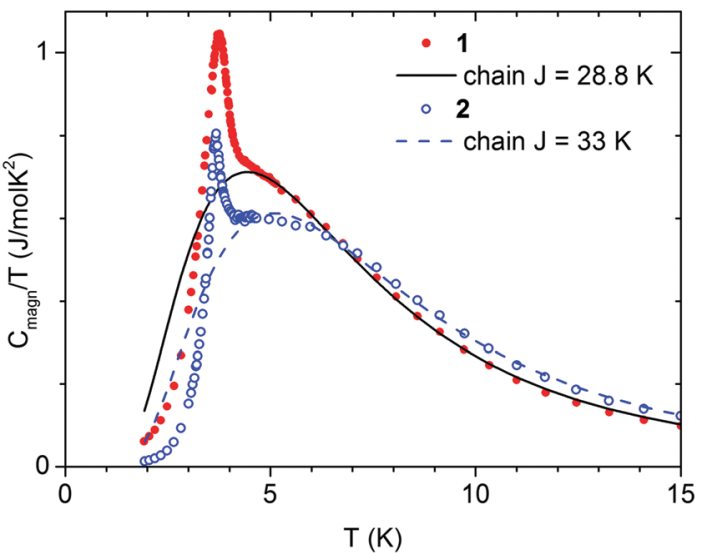

Fig. 7 Magnetic contribution $C_{\text {magn }}$ of the specific heat, obtained for compounds $\mathbf{1}$ and $\mathbf{2}$, shown as $C / T$. The lines denote the fitted contribution related to the exchange interaction $J$ within chains of Ising spins.

and $J / k_{\mathrm{B}}=33.2(4) \mathrm{K}$. The $C_{\text {lattice }}$ and $C_{\text {chain }}$ curves, calculated using these parameters, are drawn in Fig. S18 and S19 (ESI $\dagger$ ). The magnetic contribution to specific heat, obtained by subtracting $C_{\text {magn }}=C-C_{\text {lattice, }}$ is shown in Fig. 7. The entropy change, calculated by integrating $C_{\text {magn }} / T$ in the range from 2 to $40 \mathrm{~K}$, is 5.53 for 1 and $5.37 \mathrm{~J}(\mathrm{~mol} \mathrm{~K})^{-1}$ for 2 , which is close to the expected $N_{\mathrm{A}} k_{\mathrm{B}} \ln 2=5.76 \mathrm{~J}(\mathrm{~mol} \mathrm{~K})^{-1}$. Only a fraction of this entropy change is below $T_{\mathrm{c}}\left(0.69\right.$ and $0.34 \mathrm{~J}(\mathrm{~mol} \mathrm{~K})^{-1}$, respectively). Such behavior is characteristic for quasi-one dimensional systems. ${ }^{87}$ Most importantly, the $J$ values obtained from the analysis of calorimetric measurements agree very well with the $J$ values obtained from the analysis of magnetic measurements.

\section{Dynamic magnetic properties}

Fig. 8 presents the temperature dependence of the AC magnetic susceptibility of $\mathbf{1}$ and $\mathbf{2}$ measured at various frequencies and zero DC field. In Fig. S20 (ESI $\dagger$ ) also the data collected in field close to $H_{\mathrm{c}}$ are shown. As seen, in zero DC field the frequency dispersion occurs in the temperature range much below $T_{\mathrm{c}}$ but in field close to $H_{\mathrm{c}}$ this temperature range is considerably extended and the maximum value of $\chi$ considerably increases, especially for 2 . In addition, for 2 the maximum of $\chi^{\prime \prime}$ at first increases with increasing temperature and then decreases.

The Mydosh parameter $\phi=\Delta T_{\mathrm{m}} /\left[T_{\mathrm{m}} \Delta(\log f)\right]$ in zero DC field determined from the temperature shift of $\chi^{\prime \prime}$ is $\phi \approx 0.15$ for 1 and $\phi \approx 0.10$ for 2 , which is in the range expected for superparamagnets and single chain magnets. ${ }^{88}$

The frequency behavior of $\chi_{\mathrm{AC}}$ observed for compounds $\mathbf{1}$ and 2 at various temperatures in zero field is presented in Fig. 9. For analysis the generalized Debye formula was used, which written for a single distribution of relaxation times has the following form:

$$
\chi=\chi^{\prime}-i \chi^{\prime \prime}=\chi_{\infty}+\frac{\chi_{0}-\chi_{\infty}}{1+(i \omega \tau)^{1-\alpha}}
$$

The meaning of the symbols is as follows: $\chi_{0}$ and $\chi_{\infty}$ are the susceptibilities in the limits of zero and infinite frequencies, respectively, $\tau$ is the mean relaxation time and the parameter $\alpha$ describes the width of the relaxation time distribution $(0 \leq \alpha \leq 1)$. 


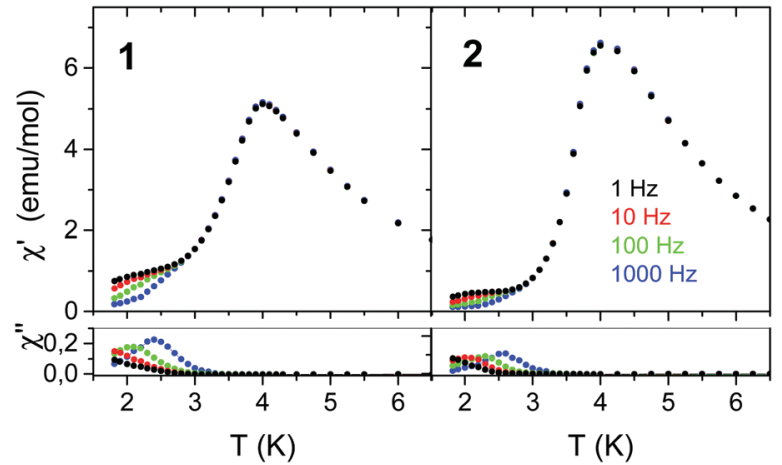

Fig. 8 Temperature dependence of $\chi_{\text {AC }}$ registered at various frequencies for $\mathbf{1}$ and $\mathbf{2}$ in zero DC field.

The data of zero field for 1 and $\mathbf{2}$ could be well fitted with a single distribution. A small contribution of a second distribution observed for $\mathbf{1}$ at the lowest temperatures and lowest frequencies (see also the Cole-Cole plot; Fig. S21 and S22, ESI $\dagger$ ) was omitted in the analysis. For both compounds the $\alpha$ parameter is relatively small $(\sim 0.2)$ at the upper temperature limit but increases with decreasing temperature, becoming $\sim 0.55$ at the lower temperature limit of $1.8 \mathrm{~K}$ (Tables S4 and S5, ESI $\dagger$ ). The corresponding data in field could be successfully fitted only for 1 assuming one distribution (the data for 2 were more complex and could not be fitted). The values of $\alpha$ determined for 1 in field were $0.45-0.54$ in the corresponding temperature range $1.8-3.0 \mathrm{~K}$. It is worth to note the higher value of $\alpha$ at the upper temperature limit in relation to zero field.

The values of relaxation times for 1 and 2 obtained from fits are plotted as $\ln \tau$ vs. $1 / T$ dependence in Fig. 10 and fitted using the Arrhenius equation

$$
\tau=\tau_{0} \exp \left(\Delta E / k_{\mathrm{B}} T\right)
$$

where $\tau_{0}$ is a prefactor and $\Delta E$ is the energy barrier for the relaxation process.
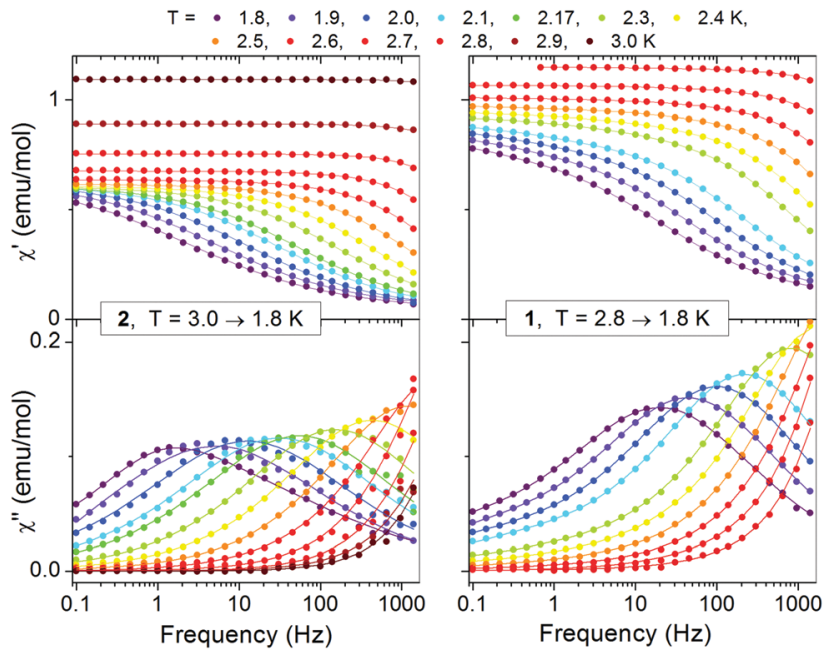

Fig. 9 Frequency dependent AC susceptibility for $\mathbf{2}$ (left) and $\mathbf{1}$ (right) in $H_{\mathrm{DC}}=0$ Oe. Solid lines are fits of the generalized Debye relaxation model.

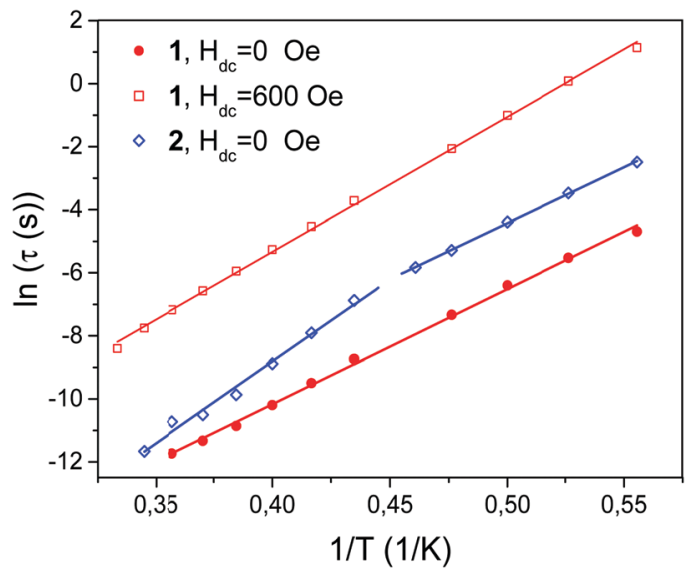

Fig. 10 Temperature dependence of the relaxation time $\tau$ determined at $H_{\mathrm{dc}}=0$ Oe for $\mathbf{1}$ and $\mathbf{2}$ and at $H_{\mathrm{dc}}=600$ Oe for $\mathbf{1}$. Straight lines were fitted using the Arrhenius equation.

As seen in Fig. 10, the straight line dependence in the whole temperature range used (red lines) was obtained for $\mathbf{1}$ in both zero DC field and 600 Oe DC field. The following values of parameters for zero DC field were obtained from the plot: $\Delta E / k_{\mathrm{B}}=36.5 \pm 2 \mathrm{~K}, \tau_{0}=(1.77 \pm 0.50) \times 10^{-11} \mathrm{~s}$. The corresponding values for 600 Oe field were as follows: $\Delta E / k_{\mathrm{B}}=42.8 \pm 2 \mathrm{~K}$, $\tau_{0}=(1.76 \pm 0.45) \times 10^{-10} \mathrm{~s}$. It is noted that the value of $\tau_{0}$ increased in field by one order of magnitude, which is in agreement with ref. 89.

For 2 two straight line intervals were obtained for $H_{\mathrm{dc}}=0 \mathrm{Oe}$ with the crossover temperature $T^{*} \sim 2.2 \mathrm{~K}$. Such intervals are usually interpreted as the finite chain regime (at lower temperatures; denoted below with subscript $k=1$ ) and the infinite chain regime (at higher temperatures; $k=2$ ). Thus, for 2 , $\tau_{01}=2.4 \times 10^{-10} \mathrm{~s}, \Delta E_{1} / k_{\mathrm{B}}=35.5(1.0) \mathrm{K}$ and $\tau_{02}=1.4 \times 10^{-13} \mathrm{~s}$, $\Delta E_{2} / k_{\mathrm{B}}=51.9(2.6) \mathrm{K}$. It is noted that the value $\Delta E_{1}$ is close to the value $36.5 \mathrm{~K}$ of 1 . The corresponding parameters for 400 Oe field, as already mentioned above, could not be reliably determined.

The crossover from $k=1$ to $k=2$ observed for 2 at $T^{*}$ can be used to estimate the chain length $n$ through the relation $2 n$ $\exp \left(-2 J s^{2} / k_{\mathrm{B}} T^{*}\right)=1$, assuming the same length of all chains. ${ }^{16}$ For $J=32 \mathrm{~K}$ and $T^{*}=2.2 \mathrm{~K}$ the chains are fairly long with $n \sim 700$ links.

\section{Discussion of the magnetic properties}

According to Coulon et al. ${ }^{16} \Delta E$ for anisotropic Heisenberg systems $\Delta E_{\mathrm{k}}$ may be written as composed of the following two terms:

$$
\Delta E_{\mathrm{k}}=k \Delta_{\xi}+\Delta_{\mathrm{A}}
$$

where $\Delta_{\xi}$ is the energy needed to create a domain wall and $\Delta_{\mathrm{A}}$ is the anisotropy energy, which is interpreted as an energy barrier for a single anisotropic spin inside a narrow domain wall, where it feels no local field. ${ }^{16}$ However, in the case of Ising systems with spin $s=1 / 2$ (no zero field splitting) the interpretation of $\Delta_{\mathrm{A}}$ is still not clear. ${ }^{90}$ With two slopes obtained for 2 both $\Delta_{\xi}$ and $\Delta_{\mathrm{A}}$ can be determined from eqn (12) as $\Delta_{\xi}=\Delta E_{2}-\Delta E_{1}=16.4 \mathrm{~K}$ and $\Delta_{\mathrm{A}}=19.1 \mathrm{~K}$. Thus, the $\Delta_{\mathrm{A}}$ value is greater than the $\Delta_{\xi}$ value, 
consistent with the assumption that $\mathbf{2}$ (and most likely $\mathbf{1}$ ) is in the Ising limit.

Initially, after the discovery of SCM, it was believed that slow relaxations may be observed only in systems with weakly interacting chains, so weakly that no magnetic ordering occurs or it occurs at very low temperature. Soon, it was demonstrated by Coulon et $a{ }^{89}{ }^{89}$ that slow relaxations can also exist in the antiferromagnetic (AF) phase and that the relaxation time is enhanced in DC magnetic field being maximum close to the antiferromagnetic-paramagnetic phase transition. Later on, slow relaxations in the AF phase were also reported by Miyasaka et al., who observed them below the blocking temperature $T_{\mathrm{B}} \sim 5 \mathrm{~K}$, significantly lower than the Néel temperature $T_{\mathrm{N}}=9.4 \mathrm{~K}$. The hysteresis loops in the AF phase, which were presented in both referenced articles, appeared due to slow relaxations of SCM. Obviously, slow relaxations in the AF phase should disappear with the increase of the interchain interactions or more precisely with the increase of the $z J^{\prime} / J$ ratio and this increase should be associated with the decrease of the $T_{\mathrm{B}} / T_{\mathrm{N}}$ ratio. This remark refers also to other $\mathrm{AF}$ compounds $\mathrm{Co}(\mathrm{NCS})_{2} \mathrm{~L}_{2}$ previously studied. ${ }^{41-45}$ All are close to the disappearance of SCMs due to significant interchain interactions.

On the other hand, all these compounds show strong relaxations in magnetic fields close to $H_{\mathrm{c}}$. We have shown that relaxations observed for 1 in 600 Oe can be described with the generalized Debye model and a single but rather broad distribution of the relaxation times $(\alpha \sim 0.5)$. The more complex relaxational behavior of 2 in field (see Fig. S20, ESI $\dagger$ ) may be related to the chosen applied field value because, as known from the previous studies, in fields above $H_{\mathrm{c}}$ the material is in the mixed phase between antiferromagnetic and paramagnetic phases. Then the 3D ferromagnetically ordered domains or fractal spin glass clusters form. ${ }^{91}$ Also the observed crossover as well as the more complex crystal structure having two directions of $\mathrm{N}_{\mathrm{pyr}}-\mathrm{Co}-\mathrm{N}_{\mathrm{pyr}}$ vectors $\left(\mathrm{N}_{\mathrm{pyr}}\right.$ is the nitrogen atom of pyridine) may influence the relaxational behavior of 2 .

It is noted that in $\mathbf{1}$ and $\mathbf{2}$ as well as in other compounds of the $\mathrm{Co}(\mathrm{NCS})_{2} \mathrm{~L}_{2}$ family the only possible interchain interactions are dipolar interactions. Sometimes they lead to AF, and sometimes to FM interactions. For a better understanding of the magnetic properties of this family the knowledge of the easy direction of anisotropy is necessary.

We do not see a clear difference in magnetic properties between trans and cis coordination of Co-ions in $\mathbf{1}$ and 2. The eventual difference is so small that it is obscured by the difference in crystal structures and large distortion of the coordination octahedron.

\section{Computational studies}

Magnetic coupling. The investigation of the intra-chain magnetic coupling for compounds $\mathbf{1}$ and $\mathbf{2}$ is based on the dinuclear $\mathrm{Co}$ (II) model complexes representing a cutout of the corresponding molecular chain (1: L-py = 4-vinylpyridine; 2: L-py $=4$-benzoylpyridine). Since the repeating units of the molecular chains $\left(\left[\mathrm{Co}(\mathrm{NCS})_{2}(\mathrm{~L}-\mathrm{py})_{2}\right]\right)$ are neutral, the representation of the full coordination sphere of two adjacent $\mathrm{Co}$ (II) ions in the dinuclear model complex leads to an overall charge, which needs to be compensated within the model. Therefore, the model complex was terminated by two additional $\mathrm{Na}(\mathrm{I})$ ions at the positions of adjacent $\mathrm{Co}$ (II) ions in the infinite chains. This leads to the computational model complex $\mathrm{Na}_{2}\left[\mathrm{Co}_{2}(\mathrm{NCS})_{6}(\mathrm{~L}-\mathrm{py})_{4}\right]$ (see Fig. S23, $\mathrm{ESI} \dagger$ ), for which the broken-symmetry formalism was employed to calculate the pairwise interactions within the chains of compounds 1 and 2. The constrained DFT (CDFT) approach was utilized for the calculations, as it has been proven to be more efficient with respect to convergence issues than the standard broken-symmetry DFT (BS-DFT) approach. ${ }^{92}$ Moreover, the CDFT approach usually leads to superior results for magnetic exchange couplings as compared to those generated with the standard BS-DFT approach. ${ }^{93,94}$ In fact, the coupling constants $J$ obtained with CDFT (1: $27.6 \mathrm{~K} ; 2$ : $35.3 \mathrm{~K}$ ) reproduce the experimental ferromagnetic ordering. Details are summarized in Table S6 (ESI $\dagger$ ) and the corresponding spin densities for both compounds are depicted in Fig. S24 and S25 (ESI $\dagger$ ). It should be noted here that in the case of 2 the BS-DFT approach predicts an antiferromagnetic interaction which is in conflict with the experiments. One major issue within the BS-DFT calculations is an overestimated spin delocalization onto the terminal NCS ligands leading to decreased spin density on the two bridging NCS units. This issue arises from the isolated character of the employed models for the representation of the infinite molecular chains. In the model systems the spin density of the unpaired electrons from the $\mathrm{Co}$ (II) ions is consequently delocalized over a larger spatial region. An alternative option to tackle this issue could be the utilization of larger model systems containing more repeating units, however, at significantly higher computational costs.

Our results with the CDFT calculations show that employing constraints to restrict the spin densities on the $\mathrm{Co}$ (II) centers and their first coordination sphere allows the use of dinuclear model systems to qualitatively reproduce the magnetic coupling in 1 and 2. To gain further insight, we performed calculations for which the sodium ions were replaced by simple point charges located at the positions of the metal ions. In contradiction to the experiment this leads to an antiferromagnetic ground state in the case of $1(J=-41.3 \mathrm{~K})$ and a weak ferromagnetic coupling in the case of $2(J=12.7 \mathrm{~K})$. Thus, we conclude that a reasonable chemical representation of the metal centers at the terminal positions of the model fragment is required to reproduce the experimental results, which cannot be achieved by simple point charges. To further probe the possible reduction of the computational model we also tested to substitute the apical pyridinebased co-ligands by an unsubstituted pyridine. For both cases this results in the prediction of a rather strong antiferromagnetic coupling (1: $J=-108.1 \mathrm{~K}, 2: J=-86.9 \mathrm{~K})$. This clearly indicates that also the electronic properties of the apical co-ligands might play a crucial role.

As a result, CDFT calculations on the sodium terminated dinuclear model system are suitable to describe the intra-chain interactions in compounds $\mathbf{1}$ and 2 . These calculations are in agreement with the observed small differences in magnetic coupling as the two configurations at the cobalt centers are concerned (1: trans- and 2 cis-position). 
Single-ion anisotropy. $A b$ initio calculations have been performed to gain further insight into the magnetic anisotropy of the single ions for compounds $\mathbf{1}$ and 2 . To adequately describe the $[\mathrm{Ar}] 3 \mathrm{~d}^{7}$ electronic configuration of $\mathrm{Co}(\mathrm{II})$ ions and consequently their magnetic properties it is inevitable to apply multireference computational approaches. However, these calculations are costly in terms of computational time, and thus, at this level of theory only molecular fragments with one $\mathrm{Co}$ (II) metal center can be investigated. In accordance with our above-mentioned results the model structure for the calculation of the single-ion anisotropies of $\mathbf{1}$ and $\mathbf{2}$ is based on mononuclear $\mathrm{Co}$ (II) fragments with sodium ions at the terminating positions $\left(\mathrm{Na}_{2}\left[\mathrm{Co}(\mathrm{NCS})_{4}(\mathrm{~L}-\mathrm{py})_{2}\right]\right.$, see Fig. S26, ESI $\left.\dagger\right)$. Since the asymmetric unit of compound 1 contains two crystallographically independent Co(II) centers two model complexes had to be used which differ in the orientation of vinylpyridine planes with respect to the direction of the chain and are further denoted as 1-Co1 (perpendicular) and 1-Co2 (parallel).

In general, high-spin $\mathrm{Co}(\mathrm{II})$ ions in an octahedral geometry possess a ${ }^{4} \mathrm{~T}_{1 \mathrm{~g}}$ ground state which is primarily responsible for their magnetic properties due to considerable energy gaps to higher quartet $\left({ }^{4} \mathrm{~T}_{2 \mathrm{~g}},{ }^{4} \mathrm{~A}_{2 \mathrm{~g}}\right)$ and doublet states $\left({ }^{2} \mathrm{G},{ }^{2} \mathrm{P}\right.$, etc. $)$. Nevertheless, the higher energetic states have a slight influence on the electronic ground state, and thus have to be taken into account. Table S7 (ESI $\dagger$ ) lists the corresponding CASSCF and CASPT2 energies for all quartet and the 12 lowest doublet states of 1-Co1, 1-Co2, and 2. As it can be seen the high-spin ${ }^{4} \mathrm{~F}$ multiplet with its ${ }^{4} \mathrm{~T}_{1 \mathrm{~g}},{ }^{4} \mathrm{~T}_{2 \mathrm{~g}}$, and ${ }^{4} \mathrm{~A}_{2 \mathrm{~g}}$ subterms is the ground state in all cases independent of whether dynamic correlation is excluded (CASSCF) or included (CASPT2). Nevertheless, dynamic correlation is essential to reasonably describe the doublet states as it can be seen by the significant changes in their relative energies upon inclusion. For CASPT2 the lowest doublet states are well separated from the lowest quartet state with energy gaps of 9173, 9030, and $9791 \mathrm{~cm}^{-1}$ for 1-Co1, 1-Co2, and 2, respectively. However, the description of these individual states is not sufficient to get an accurate insight into the magnetic properties due to the lack of state-mixing and spin-orbit coupling.

RASSI-SO/SINGLE_ANISO calculations on the basis of the CASPT2 wave functions have been performed to adequately describe the energetic states. This leads to 6 doubly degenerated spin-orbit coupled states $(J=1 / 2,3 / 2$, and $5 / 2)$, denoted as Kramers doublets (KDs), with predominant contribution from the ${ }^{4} \mathrm{~T}_{1 \mathrm{~g}}$ subterm of the ${ }^{4} \mathrm{~F}$ multiplet. However, even at room temperature only the lowest two KDs are expected to be thermally populated, due to the relative energies of the higher KD states (see Table S8, ESI $\dagger$ ). The alternating orientation of the 4-vinylpyridine co-ligands in the case of $\mathbf{1}$ has a slight influence on the calculated energy gap between the ground and the first excited KD. The parallel arrangement of 4-vinylpyridine with respect to the chain orientation (1-Co2) leads to a slightly higher energy gap of $192 \mathrm{~cm}^{-1}$ as compared to the perpendicular case (1-Co1) with $183 \mathrm{~cm}^{-1}$. On the other hand, for compound 2 both parallel and perpendicular orientations of the 4-benzoylpyridine co-ligand are observed at a single $\mathrm{Co}$ (II) ion which in this case is associated with a significantly higher first excited KD at $270 \mathrm{~cm}^{-1}$. However, this effect cannot be attributed to a single structural parameter, due to the additional differences in the $(\mathrm{NCS})_{4}$ coordination environment at the $\mathrm{Co}(\mathrm{II})$ centers (1: cis, 2: trans) as well as differences in the structural and electronic properties imposed by the substituents at the co-ligands.

Calculated zero-field splitting (ZFS) parameters and $g$ values for an effective spin of $S_{\text {eff }}=3 / 2$ are summarized in Table 3 and show for both compounds the presence of an easy-axis anisotropy. In accordance with the above-mentioned results a larger absolute axial ZFS parameter $D$ is obtained for $2\left(-124.99 \mathrm{~cm}^{-1}\right)$ as compared to 1-Co1 $\left(-85.87 \mathrm{~cm}^{-1}\right)$ and 1-Co2 $\left(-83.24 \mathrm{~cm}^{-1}\right)$. Additionally, in all cases a significant rhombic distortion in terms of large absolute $E$ values can be observed (1-Co1: $-18.54 \mathrm{~cm}^{-1}$; 1-Co2: $-27.67 \mathrm{~cm}^{-1} ; 2:-29.69 \mathrm{~cm}^{-1}$ ) leading to remarkable $E / D$ ratios.

The corresponding anisotropy axes are depicted in Fig. 11. In all cases a nearly parallel alignment of the main anisotropy axis with the $\mathrm{N}-\mathrm{N}$ vector of the two apical pyridine-based co-ligands can be found. The angle between the $\mathrm{N}-\mathrm{N}$ vector and the main anisotropy axis is found to be $2.5,2.8$, and $0.3^{\circ}$ for 1-Co1, 1-Co2, and 2, respectively. In both compounds the corresponding hard plane of magnetization is formed within the $\mathrm{S}_{2} \mathrm{~N}_{2}$ coordination plane of the four NCS ligands (angles between the hard plane and the $\mathrm{S}_{2} \mathrm{~N}_{2}$ coordination plane: 1-Co1: $2.4^{\circ}$, 1-Co2: $3.1^{\circ}, 2: 1.6^{\circ}$ ). The basic orientation of the two hard-axes approximately along the $\mathrm{Co}-\mathrm{N}$ and $\mathrm{Co}-\mathrm{S}$ bonds can explain the noticeable rhombic ZFS parameter $E$ due to a different electronic structure of these $\mathrm{N}$ and $\mathrm{S}$ donor atoms.

The calculated $g$ values $\left(S_{\text {eff }}=3 / 2\right)$ given in Table 4 show in accordance with the ZFS an easy-axis anisotropy $\left(g_{z}>g_{x}, g_{y}\right)$ with $g_{z}$ values of 2.980, 2.974, and 3.291 for 1-Co1, 1-Co2, and 2, respectively. The large $g_{z}$ values as compared to (pseudo)tetrahedrally coordinated $\mathrm{Co}$ (II) complexes $^{95}$ are the result of a strong spin-orbit contribution which is most pronounced in the case of 2. It is interesting to note that this goes along with the smallest deviation from an ideal octahedral coordination sphere in the case of 2 as obtained by continuous shape measures $\left(S\left(\mathrm{O}_{\mathrm{h}}\right)\right.$ for 1-Co1: 1.057, 1-Co2: 1.130, and 2: 0.865). ${ }^{96,97}$

The calculated $g$ tensor components for the two lowest KDs within an effective spin formalism of $S_{\text {eff }}=1 / 2$ are listed in Table 4 . For both compounds 1 and 2 the ground state KD possesses an easy-axis anisotropy which is in agreement with the previous results (for $S_{\text {eff }}=3 / 2$ ). Fig. S27 (ESI $\dagger$ ) shows the corresponding ground state magnetic axes for 1 and 2 . The calculated ground state $g_{z}$ values (1-Co1: 8.445, 1-Co2: 7.997, 2: 8.747) are slightly overestimated as compared to the experimental data (1: 7.3(2), 2: 7.0(2)).

Table 3 Calculated ZFS parameters and values of the $g$ tensor for the two lowest KDs of the ${ }^{4} T_{1 g}$ term $\left(S_{\text {eff }}=3 / 2\right)$ for 1 and $\mathbf{2}$

\begin{tabular}{llll}
\hline & 1-Co1 & 1-Co2 & 2 \\
\hline$D / \mathrm{cm}^{-1}$ & -85.87 & -83.24 & -124.99 \\
$E / \mathrm{cm}^{-1}$ & -18.54 & -27.67 & -29.69 \\
$E / \mathrm{D}$ & 0.22 & 0.33 & 0.24 \\
& & & \\
$g_{x}$ & 1.971 & 1.885 & 1.683 \\
$g_{y}$ & 2.233 & 2.365 & 1.823 \\
$g_{z}$ & 2.980 & 2.974 & 3.291
\end{tabular}



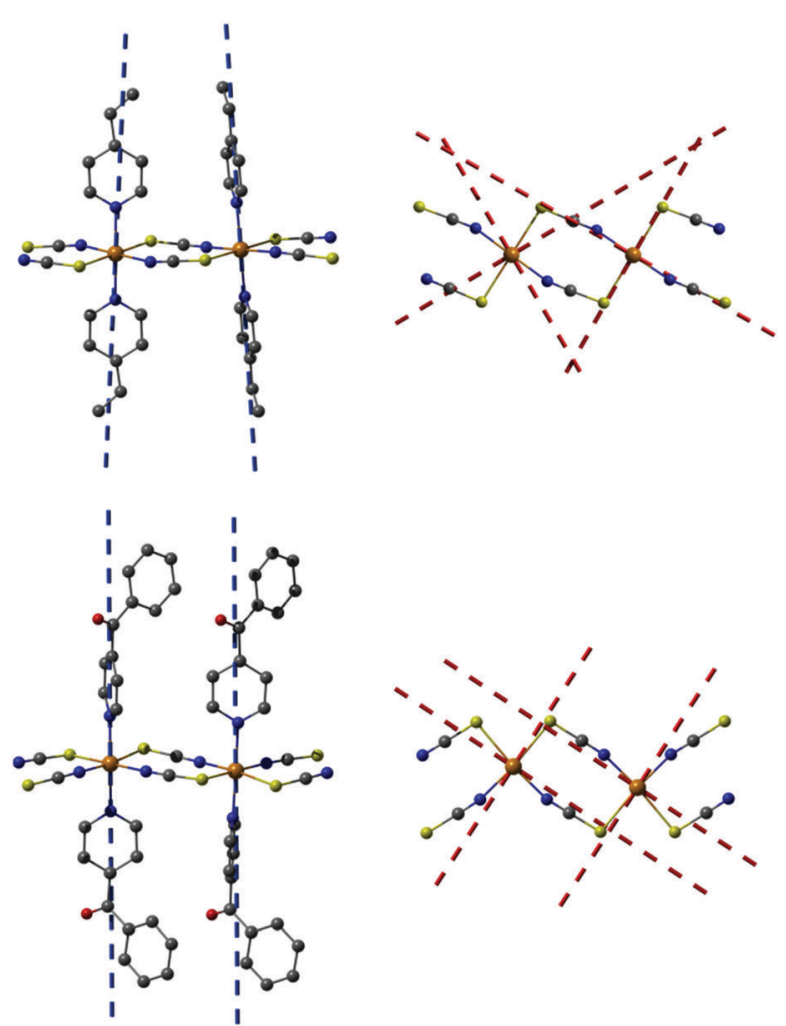

Fig. $11 A b$ initio calculated $\left(S_{\text {eff }}=3 / 2\right)$ anisotropy axes (blue dashed lines: easy-axes; red dashed lines: hard-axes) of 1-Co1, 1-Co2, and 2 projected onto dinuclear Co(॥) fragments of 1 (top) and 2 (bottom). The angle between the two easy-axes of $1-\mathrm{Co} 1$ and $1-\mathrm{Co} 2$ is $9.0^{\circ}$. In the respective top view on the right hand side the hydrogen atoms as well as pyridinebased co-ligands are omitted for clarity.

Noteworthily, the perpendicular arrangement of 4-vinylpyridine with respect to the chain orientation (1-Co1) leads to a slightly higher $g_{z}$ value as compared to the parallel case (1-Co2). The first excited KD in $\mathbf{1}$ and $\mathbf{2}$ also shows easy-axis anisotropy, but with smaller $g_{z}$ values and larger transversal components $g_{x}$ and $g_{y}$. The corresponding principal axes for the first excited $\mathrm{KD}$ are depicted in Fig. S28 (ESI $\dagger$ ). For compound 2 the orientation of the principal axes is similar to what was observed for the ground state, whereas this is surprisingly not the case for the $\mathrm{Co}$ (II) centers of 1-Co1 and 1-Co2. For the latter cases the easy-axes of the first excited state are within the $\mathrm{S}_{2} \mathrm{~N}_{2}$ coordination plane and oriented perpendicular to the corresponding plane of the aromatic ring system of the 4-vinylpyridine co-ligands.

Table 4 Main values of the $g$ tensor for the two lowest KDs $\left(S_{\text {eff }}=1 / 2\right)$ and their relative energies for $\mathbf{1}$ and $\mathbf{2}$

\begin{tabular}{lllll}
\hline $\mathrm{KD}$ & & 1-Co1 & 1-Co2 & 2 \\
\hline 1 & $E_{\mathrm{KD}} / \mathrm{cm}^{-1}$ & 0 & 0 & 0 \\
& $g_{x}$ & 1.198 & 1.532 & 1.397 \\
& $g_{y}$ & 1.484 & 2.300 & 1.486 \\
& $g_{z}$ & 8.445 & 7.997 & 8.747 \\
& & & & \\
& & 183 & 192 & 270 \\
& $E_{\mathrm{KD}} / \mathrm{cm}^{-1}$ & 2.905 & 2.432 & 0.424 \\
& $g_{x}$ & 2.975 & 2.507 & 1.807 \\
& $g_{y}$ & 4.840 & 4.938 & 4.194
\end{tabular}

There is an obvious discrepancy between experimentally estimated effective barriers and the calculated single-ion barriers in terms of their first excited KD energies. Thus, the presence of dominant relaxation processes other than the thermal Orbach process can be assumed. Concerning quantum tunneling within a single Co(II) ion fragment Fig. S29 and S30 (ESI $\dagger$ ) show the average dipole transition matrix elements for the first two KDs of 1 and 2. Obviously, for all model systems a considerable quantum tunneling of magnetization would be expected due to the large dipole transition matrix elements within the ground state $\mathrm{KD}$ (1-Co1: 0.447; 1-Co2: 0.639; 2: 0.480). In contrast to 2, the first excited KD of 1-Co1 and 1-Co2 shows no large $\bar{\mu}_{z}$ value due to the change of the easy-axis orientation. Recently, a similar discrepancy $\left(U_{\text {calc }}=264 \mathrm{~cm}^{-1}\right.$ and $U_{\text {eff }}=25 \mathrm{~cm}^{-1}$ ) has been reported for a mononuclear octahedral $\mathrm{Co}(\mathrm{II})$ compound $\left(\left[\mathrm{Co}\left(\mathrm{H}_{2} \mathrm{O}\right)_{2}\left(\mathrm{CH}_{3} \mathrm{COO}\right)_{2}(\mathrm{py})_{2}\right]\right)$ with two apical pyridine ligands for which a two-phonon Raman process was proposed. ${ }^{98}$ Moreover, it should be noted that $\mathbf{1}$ and $\mathbf{2}$ are not single-ion complexes but represent more complex magnetically coupled systems. Nevertheless, the performed single-ion ab initio calculations help to evaluate the axial anisotropy which revealed a slightly higher axial anisotropy in the case of 2 which goes together with a stronger intra-chain magnetic coupling. Due to the identical NCS-bridged equatorial coordination chains the axial anisotropy can be directly tuned by the apical co-ligands with their electronic influences.

\section{Conclusions}

The major goal of this work consists of investigations of the influence of metal coordination and the crystal structure on the magnetic properties of $1 \mathrm{D}$ Co-thiocyanato coordination polymers. Therefore, two new compounds of the general formula $\left[\mathrm{Co}(\mathrm{NCS})_{2} \mathrm{~L}_{2}\right]_{n}$ were synthesized (L is 4-vinylpyridine (1) or 4-benzoyl pyridine (2)). They are built up of ferromagnetic chains, which are weakly antiferromagnetically coupled, so they show magnetic ordering and a metamagnetic transition. While 1 shows a trans configuration of the anionic ligands along the exchange path, the configuration is different (cis) for 2 . This different configuration results in slightly greater magnetic exchange for 2 . Both compounds show singlechain magnet relaxations in the antiferromagnetic state. The intra-chain magnetic coupling obtained by CDFT calculations utilizing the corresponding dinuclear $\mathrm{Co}$ (II) fragments of $\mathbf{1}$ and $\mathbf{2}$ as models is in agreement with the experimental results. Ab initio calculations revealed the ground state easy-axis anisotropy in all cases with the easy-axis of magnetization aligned along the $\mathrm{N}-\mathrm{N}$ vector of the pyridine-based apical ligands. Moreover, the calculations reveal the presence of significant rhombic ZFS as evidenced by large $E$ values. The single-ion calculations clearly show that structural and electronic properties of the apical co-ligands influence the magnetic properties, e.g. in terms of the $g_{z}$ values. However, in $\mathbf{1}$ the alternating arrangement of the 4-vinylpyridine co-ligands (parallel and perpendicular) with respect to the chain orientation leads to a compensation of the higher magnetic anisotropy in the perpendicular arrangement (1-Co1). Therefore, further studies are planned to determine 
experimentally the easy direction of magnetic anisotropy and clarify the role of dipolar interactions leading to magnetic ordering, which is necessary to fully understand the variety of magnetic properties for this family of compounds.

\section{Acknowledgements}

This project was supported by the Deutsche Forschungsgemeinschaft (Project No. NA 720/5-1) and the State of SchleswigHolstein. We thank Professor Dr Wolfgang Bensch for access to his experimental facility. ZT thanks National Science Centre Poland for financial support granted under decision DEC-2013/ 11/B/ST3/03799. The research was in part carried out with the equipment purchased with the support of European Regional Development Fund within the Polish Innovation Economy Operational Program (POIG.02.01.00-12-023/08).

\section{References}

1 K. Liu, W. Shi and P. Cheng, Coord. Chem. Rev., 2015, 289290, 74-122.

2 A. Caneschi, D. Gatteschi and F. Totti, Coord. Chem. Rev., 2015, 289-290, 357-378.

3 M. Atanasov, D. Aravena, E. Suturina, E. Bill, D. Maganas and F. Neese, Coord. Chem. Rev., 2015, 289-290, 177-214.

4 Y. Z. Zheng, G. J. Zhou, Z. Zheng and R. E. P. Winpenny, Chem. Soc. Rev., 2014, 43, 1462-1475.

5 J. M. Clemente-Juan, E. Coronado and A. Gaita-Arino, Chem. Soc. Rev., 2012, 41, 7464-7478.

6 D.-F. Weng, Z.-M. Wang and S. Gao, Chem. Soc. Rev., 2011, 40, 3157-3181.

7 X. Y. Wang, C. Avendano and K. R. Dunbar, Chem. Soc. Rev., 2011, 40, 3213-3238.

8 C. Train, M. Gruselle and M. Verdaguer, Chem. Soc. Rev., 2011, 40, 3297-3312.

9 D. R. Talham and M. W. Meisel, Chem. Soc. Rev., 2011, 40, 3356-3365.

10 S. Sanvito, Chem. Soc. Rev., 2011, 40, 3336-3355.

11 J. S. Miller and D. Gatteschi, Chem. Soc. Rev., 2011, 40, 3065-3066.

12 J. S. Miller, Chem. Soc. Rev., 2011, 40, 3266-3296.

13 J. Mroziński, Coord. Chem. Rev., 2005, 249, 2534-2548.

14 C. Coulon, V. Pianet, M. Urdampilleta and R. Clérac, in Molecular Nanomagnets and Related Phenomena, ed. S. Gao, Springer, Berlin Heidelberg, 2015, ch. 154, vol. 164, pp. 143-184.

15 S. Dhers, H. L. C. Feltham and S. Brooker, Coord. Chem. Rev., 2015, 296, 24-44.

16 C. Coulon, H. Miyasaka and R. Clérac, Struct. Bonding, 2006, 122, 163-206.

17 H. Miyasaka and R. Clérac, Bull. Chem. Soc. Jpn., 2005, 78, 1725-1748.

18 L. Bogani, A. Vindigni, R. Sessoli and D. Gatteschi, J. Mater. Chem., 2008, 18, 4733-4880.

19 W.-X. Zhang, R. Ishikawa, B. Breedlovea and M. Yamashita, RSC Adv., 2013, 3, 3772-3798.
20 H.-L. Sun, Z.-M. Wang and S. Gao, Coord. Chem. Rev., 2010, 254, 1081-1100.

21 R. Lescouëzec, L. M. Toma, J. Vaissermann, M. Verdaguer, F. S. Delgado, C. Ruiz-Pérez, F. Lloret and M. Julve, Coord. Chem. Rev., 2005, 249, 2691-2729.

22 G. Bhargavi, M. V. Rajasekharan, J. P. Costes and J. P. Tuchagues, Dalton Trans., 2013, 42, 8113-8123.

23 D.-P. Dong, Y.-J. Zhang, H. Zheng, P.-F. Zhuang, L. Zhao, Y. Xu, J. Hu, T. Liu and C.-Y. Duan, Dalton Trans., 2013, 42, 7693-7698.

24 P. Hu, C. Zhang, Y. Gao, Y. Li, Y. Ma, L. Li and D. Liao, Inorg. Chim. Acta, 2013, 398, 136-140.

25 X.-B. Li, G.-M. Zhuang, X. Wang, K. Wang and E.-Q. Gao, Chem. Commun., 2013, 49, 1814-1816.

26 K. S. Lim and C. S. Hong, Dalton Trans., 2013, 42, 14941-14950.

27 T. Liu, H. Zheng, S. Kang, Y. Shiota, S. Hayami, M. Mito, O. Sato, K. Yoshizawa, S. Kanegawa and C. Duan, Nat. Commun., 2013, 4, 1-7.

28 V. Tangoulis, M. Lalia-Kantouri, M. Gdaniec, C. Papadopoulos, V. Miletic and A. Czapik, Inorg. Chem., 2013, 52, 6559-6569.

29 D.-F. Weng, B.-W. Wang, Z.-M. Wang and S. Gao, Coord. Chem. Rev., 2013, 257, 2484-2490.

30 M.-X. Yao, Q. Zheng, K. Qian, Y. Song, S. Gao and J.-L. Zuo, Chem. - Eur. J., 2013, 19, 294-303.

31 X. Chen, S.-Q. Wu, A.-L. Cui and H.-Z. Kou, Chem. Commun., 2014, 50, 2120-2122.

32 V. Mougel, L. Chatelain, J. Hermle, R. Caciuffo, E. Colineau, F. Tuna, N. Magnani, A. de Geyer, J. Pécaut and M. Mazzanti, Angew. Chem., 2014, 126, 838-842.

33 E. V. Peresypkina, A. M. Majcher, M. Rams and K. E. Vostrikova, Chem. Commun., 2014, 50, 7150-7153.

34 J. Ru, F. Gao, T. Wu, M.-X. Yao, Y.-Z. Li and J.-L. Zuo, Dalton Trans., 2014, 43, 933-936.

35 H. Miyasaka, T. Madanbashi, A. Saitoh, N. Motokawa, R. Ishikawa, M. Yamashita, S. Bahr, W. Wernsdorfer and R. Clérac, Chem. - Eur. J., 2012, 18, 3942-3954.

36 I. Bhowmick, E. A. Hillard, P. Dechambenoit, C. Coulon, T. D. Harris and R. Clerac, Chem. Commun., 2012, 48, 9717-9719.

37 Z. Tomkowicz, M. Rams, M. Bałanda, S. Foro, H. Nojiri, Y. Krupskaya, V. Kataev, B. Büchner, S. K. Nayak, J. V. Yakhmi and W. Haase, Inorg. Chem., 2012, 51, 9983-9994.

38 R. Lescouëzec, J. Vaissermann, C. Ruiz-Pérez, F. Lloret, R. Carrasco, M. Julve, M. Verdaguer, Y. Dromzee, D. Gatteschi and W. Wernsdorfer, Angew. Chem., 2003, 115, 1521-1524.

39 H. Miyasaka, M. Julve, M. Yamashita and R. Clérac, Inorg. Chem., 2009, 48, 3420-3437.

40 Y.-Z. Zhang, H.-H. Zhao, E. Funck and K. R. Dunbar, Angew. Chem., Int. Ed., 2015, 54, 5583-5587.

41 S. Wöhlert, J. Boeckmann, M. Wriedt and C. Näther, Angew. Chem., Int. Ed., 2011, 50, 6920-6923.

42 J. Werner, Z. Tomkowicz, M. Rams, S. G. Ebbinghaus, T. Neumann and C. Näther, Dalton Trans., 2015, 44, 14149-14158.

43 S. Wöhlert, Z. Tomkowicz, M. Rams, S. G. Ebbinghaus, L. Fink, M. U. Schmidt and C. Näther, Inorg. Chem., 2014, 53, 8298-8310. 
44 S. Wöhlert, T. Fic, Z. Tomkowicz, S. G. Ebbinghaus, M. Rams, W. Haase and C. Näther, Inorg. Chem., 2013, 52, 12947-12957.

45 S. Wöhlert, U. Ruschewitz and C. Näther, Cryst. Growth Des., 2012, 12, 2715-2718.

46 J. Werner, M. Rams, Z. Tomkowicz, T. Runčevski, R. E. Dinnebier, S. Suckert and C. Näther, Inorg. Chem., 2015, 54, 2893-2901.

47 J. Werner, M. Rams, Z. Tomkowicz and C. Näther, Dalton Trans., 2014, 43, 17333-17342.

48 S. Wöhlert, M. Wriedt, T. Fic, Z. Tomkowicz, W. Haase and C. Näther, Inorg. Chem., 2013, 52, 1061-1068.

49 J. Boeckmann, M. Wriedt and C. Näther, Chem. - Eur. J., 2012, 18, 5284-5289.

50 S. Wöhlert, T. Runčevski, R. E. Dinnebier, S. G. Ebbinghaus and C. Näther, Cryst. Growth Des., 2014, 14, 1902-1913.

51 J. Werner, T. Runčevski, R. Dinnebier, S. G. Ebbinghaus, S. Suckert and C. Näther, Eur. J. Inorg. Chem., 2015, 3236-3245.

52 C. Näther, S. Wöhlert, J. Boeckmann, M. Wriedt and I. Jeß, Z. Anorg. Allg. Chem., 2013, 639, 2696-2714.

53 J. Palion-Gazda, B. Machura, F. Lloret and M. Julve, Cryst. Growth Des., 2015, 15, 2380-2388.

54 E. Shurdha, S. H. Lapidus, P. W. Stephens, C. E. Moore, A. L. Rheingold and J. S. Miller, Inorg. Chem., 2012, 51, 9655-9665.

55 E. Shurdha, C. E. Moore, A. L. Rheingold, S. H. Lapidus, P. W. Stephens, A. M. Arif and J. S. Miller, Inorg. Chem., 2013, 52, 10583-10594.

56 F. A. Mautner, M. Scherzer, C. Berger, R. C. Fischer, R. Vicente and S. S. Massoud, Polyhedron, 2015, 85, 20-26.

57 J. Werner, Z. Tomkowicz, T. Reinert and C. Näther, Eur. J. Inorg. Chem., 2015, 3066-3075.

58 M. G. B. Drew, N. I. Gray, M. F. Cabral and J. d. O. Cabral, Acta Crystallogr., Sect. C: Cryst. Struct. Commun., 1985, 41, 1434-1437.

59 B. M. Foxman and H. Mazurek, Inorg. Chim. Acta, 1982, 59, 231-235.

60 G. D. Andreetti and P. Sgarabotto, Cryst. Struct. Commun., 1972, 1, 55-57.

61 TURBOMOLE V6.6 2014, a development of University of Karlsruhe and Forschungszentrum Karlsruhe GmbH, 19892007, TURBOMOLE GmbH, since 2007, available from www. turbomole.com.

62 E. J. Baerends, D. E. Ellis and P. Ros, Chem. Phys., 1973, 2, 41-51.

63 B. I. Dunlap, J. W. D. Connolly and J. R. Sabin, J. Chem. Phys., 1979, 71, 3396-3402.

64 C. Van Alsenoy, J. Comput. Chem., 1988, 9, 620-626.

65 J. L. Whitten, J. Chem. Phys., 1973, 58, 4496-4501.

66 A. D. Becke, Phys. Rev. A: At., Mol., Opt. Phys., 1988, 38, 3098-3100.

67 J. P. Perdew, Phys. Rev. B: Condens. Matter Mater. Phys., 1986, 33, 8822-8824.

68 F. Weigend and R. Ahlrichs, Phys. Chem. Chem. Phys., 2005, 7, 3297-3305.

69 P. H. Dederichs, S. Blügel, R. Zeller and H. Akai, Phys. Rev. Lett., 1984, 53, 2512-2515.

70 Q. Wu and T. V. Voorhis, Phys. Rev. A: At., Mol., Opt. Phys., 2005, 72, 024502.

71 A. D. Becke, J. Chem. Phys., 1993, 98, 5648-5652.

72 C. Lee, W. Yang and R. G. Parr, Phys. Rev. B: Condens. Matter Mater. Phys., 1988, 37, 785.
73 M. Valiev, E. J. Bylaska, N. Govind, K. Kowalski, T. P. Straatsma, H. J. J. V. Dam, D. Wang, J. Nieplocha, E. Apra, T. L. Windus and W. A. de Jong, Comput. Phys. Commun., 2010, 181, 1477-1489.

74 T. Soda, Y. Kitagawa, T. Onishi, Y. Takano, Y. Shigeta, H. Nagao, Y. Yoshioka and K. Yamaguchi, Chem. Phys. Lett., 2000, 319, 223-230.

75 K. Yamaguchi, T. Tsunekawa, Y. Toyoda and T. Fueno, Chem. Phys. Lett., 1988, 143, 371-376.

76 F. Aquilante, et al., J. Comput. Chem., 2016, 37, 506-541.

77 F. Aquilante, L. D. Vico, N. Ferré, G. Ghigo, P.-Å. Malmqvist, P. Neogrády, T. B. Pedersen, M. Pitoňák, M. Reiher, B. O. Roos, L. Serrano-Andrés, M. Urban, V. Veryazov and R. Lindh, J. Comput. Chem., 2010, 31, 224-247.

78 G. Karlström, R. Lindh, P.-A. Malmqvist, B. O. Roos, U. Ryde, V. Veryazov, P.-O. Widmark, M. Cossi, B. Schimmelpfennig, P. Neogrady and L. Seijo, Comput. Mater. Sci., 2003, 28, 222-239.

79 V. Veryazov, P.-O. Widmark, L. Serrano-Andres, R. Lindh and B. O. Roos, Int. J. Quantum Chem., 2004, 100, 626-635.

80 B. O. Roos, R. Lindh, P.-Å. Malmqvist, V. Veryazov and P.-O. Widmark, J. Phys. Chem. A, 2004, 108, 2851-2858.

81 B. O. Roos, R. Lindh, P.-Å. Malmqvist, V. Veryazov and P.-O. Widmark, J. Phys. Chem. A, 2005, 109, 6575-6579.

82 P.-O. Widmark, P.-A. Malmqvist and B. O. Roos, Theor. Chim. Acta, 1990, 77, 291-306.

83 M. E. Fisher, J. Math. Phys., 1963, 4, 124-135.

84 R. L. Carlin and A. J. van Duyneveldt, Magnetic properties of transition metal compounds, Springer Verlag, Berlin, 1977.

85 M. E. Fisher, Philos. Mag., 1962, 7, 1731-1743.

86 L. J. De Jongh and A. R. Miedema, Adv. Phys., 2001, 50, 947-1170.

87 R. L. Carlin, Magnetochemistry, Springer Verlag, New York, 1986.

88 J. A. Mydosh, Spin Glasses: An Experimental Introduction, Taylor and Francis, London, 1993.

89 C. Coulon, R. Clérac, W. Wernsdorfer, T. Colin, A. Saitoh, N. Motokawa and H. Miyasaka, Phys. Rev. B: Condens. Matter Mater. Phys., 2007, 76, 214422.

90 D. Gatteschi and A. Vindigni, in Molecular Magnetes, ed. J. Bartolome, F. Luis and J. F. Fernandez, Springer Berlin Heidelberg, 2014, ch. 8, pp. 191-220.

91 S. J. Etzkorn, W. Hibbs, J. S. Miller and A. J. Epstein, Phys. Rev. B: Condens. Matter Mater. Phys., 2004, 70, 134419.

92 B. Kaduk, T. Kowalczyk and T. V. Voorhis, Chem. Rev., 2012, 112, 321-370.

93 I. Rudra, Q. Wu and T. V. Voorhis, J. Chem. Phys., 2006, 124, 024103.

94 I. Rudra, Q. Wu and T. V. Voorhis, Inorg. Chem., 2007, 46, 10539-10548.

95 S. Ziegenbalg, D. Hornig, H. Görls and W. Plass, Inorg. Chem., 2016, 55, 4047-4058.

96 M. Pinsky and D. Avnir, Inorg. Chem., 1998, 37, 5575-5582.

97 H. Zabrodsky, S. Peleg and D. Avnir, IEEE T. Pattern Anal., 1995, 17, 1154-1166.

98 J. Walsh, G. Bowling, A.-M. Ariciu, N. Jailani, N. Chilton, P. Waddell, D. Collison, F. Tuna and L. Higham, Magnetochemistry, 2016, 2, 23. 